\title{
Analysis of Students' Ability to Accept M-Learning Technology: An Exploratory Study from High Schools in Vietnam
}

\author{
https://doi.org/10.3991/ijim.v15i12.22143 \\ Trinh Le Thi Tuyet \\ Dong Thap University, Dong Thap, Vietnam \\ Thao Phuong Thi Trinh $(\varpi)$ \\ Thai Nguyen University of Education, Thai Nguyen, Vietnam \\ thaottpet nue.edu.vn \\ Hang Thu Thi Nguyen \\ Thai Nguyen University of Agriculture and Forestry, \\ Thai Nguyen, Vietnam \\ Thanh Chi Nguyen \\ VNU University of Education, Vietnam National University, \\ Hanoi, Vietnam \\ Trung Tran \\ Vietnam Academy for Ethnic Minorities, Hanoi, Vietnam \\ VNU University of Education, Vietnam National University, \\ Hanoi, Vietnam
}

\begin{abstract}
Mobile phones are becoming a vital part of almost all students and teachers in the era of the Industrial Revolution 4.0. With mobile devices capable of accessing the Internet, the mobile learning method has been formed: M-learning. Many studies on this topic focused on the effectiveness of mobile technologies/applications for students to study. It is of little interest for students to use M-learning in their study and the factors affecting that decision. Based on the TAM model on technology adoption. This article analyzes and proposes factors affecting the decision to use M-learning in Vietnam - a developing country. The study used a synthesis analysis method from 238 survey samples of students. The data analysis results show that to encourage students to use Mlearning, educators need to pay attention to the design of appropriate courses to save time, improve learning efficiency, increase the mobility of learners, and necessarily introduce the convenience of courses learners through many different channels.
\end{abstract}

Keywords-Technology Acceptance Model; TAM; M-learning; Vietnam; high school 


\section{Introduction}

Nowadays, with the development of mobile phones, many educators have attempted to use these devices to improve students' learning experience. Therefore learning through mobile devices (such as smartphones and tablet PCs) called mobile learning or M-learning became popular [1]. The m-learning refers to learning and training, but the management and sharing of content and interaction are done by using mobile devices based on wireless network technology [2] [3] [4] [5] [6]. Furthermore, [7] contemplates the possibility of M-learning as a harbinger of the future of learning

Recently, many studies have been done on exploiting mobile phones' potential for pedagogical purposes in many different contexts. Studies have demonstrated that the ability to use mobile devices in learning environments effectively improves students' knowledge and learning experiences in a variety of subject areas such as science [8], [9], mathematics [10], [11] language, and art [12], [13], social science [14], engineering [15] and others. The main research directions in this topic include: (1) evaluating the effects of M-learning, (2) designing a mobile system for learning, (3) eliciting perceptions of M-learning, (4) reviewing M-learning, or (5) evaluating or exploring the factor towards M-learning. Although there have been several studies on the factors that influence learners' decision to use M-learning, most of these studies are conducted in developed countries [16], while M-learning is also at the attention of educators in developing countries recent years.

This paper is based on the TAM to study the factors affecting the students' adoption of M-learning in Vietnam - a developing country in the Asian-Pacific region. The TAM model is one of the theories in studying the application of IT innovations and new information systems [17]. However, TAM excels regarding productivityoriented (or utilitarian) systems, but the motivators to system usage may vary greatly depending on the nature of system use [18]. The paper answers the question: What factors affect the Vietnamese students' choice of studying with M-learning?

Although M-learning has been implemented at a very early stage in other countries worldwide, M-learning still faces many difficulties [19], [20]. Education in Vietnam has also been transitioning to a learner-centered teaching model, so learners' adoption of new technologies in learning is significant in determining the exchange of new forms of learning. Results of the paper answer the questions: What factors affect the choice of studying with Vietnamese students' M-learning? From there, it is possible to make suitable recommendations for the change of education in Vietnam.

\section{$2 \quad$ Literature Review}

\subsection{Overview of the M-learning}

The existence of smartphones at low prices has led to an increase in apps for distinct aspects of life such as communication, travel, entertainment, productivity, and learning. With the support of mobile devices with Internet access functions, a mobile learning method has been established: M-learning. Keegan (2002) estimates that M- 
learning will be a future learning trend. M-learning is employed using small computing mobile devices. Others simply consider M-learning as an extension of distance learning [21] or e-learning [22]. More broadly, [23] see that M-learning includes learning based on mobile devices and the learning mediated across multiple contexts using portable mobile devices.

According to [24], [25], it is possible to show some advantages of M-learning compared to other types of learning such as In-classroom activities. It is much easier for students to use mobile devices than computers, especially in arranging classrooms. SMS messages are used to send and receive information (for example, changing class schedules, checking) between teachers and students more easily, quickly, and economically than make calls. Devices such as mobile phones, tablets, e-books are more compact and more accessible to transport than briefcases full of documents, textbooks, or even laptops. Users can record points to note directly through mobile devices such as handwriting recognition, recording. Users can use the stylus to operate directly on the screen to move web pages and links more easily. It is also favorable for task assignments and collaborative learning. Many students and teachers can work in groups through Bluetooth. It can be used to learn anytime, anywhere because it is easy to use and carry. Users can take photos directly with cameras of devices such as mobile phones or tablets. Users can easily exchange documents via Bluetooth, WIFI, and 3G. It increases interest in learning for students, especially for students with low learning motivation. It also facilitates conditions for students to improve their knowledge, encourage self-study and increase their responsibility for learning.

Today, with the development of smartphones, new interactive technologies in terms of smart mobile devices and accompanied applications (apps) attract the increasing attention of many researchers to exploit in education [26]-[29], choosing the most appropriate educational ones for children. Simultaneously, there are thousands of apps available today that are difficult and problematic for both teachers and educators [30]. Therefore, it is necessary to determine students' usage habits and technology adoption to choose the right apps.

Lim et al. (2006) say that M-learning's most significant advantage is the combination of actual interaction with learning flexibility. It creates an excellent opportunity for teachers to organize collaborative learning and learner-directed learning activities, thereby helping create self-learning and independent learning motivation. Over the past decade, studies have exploited the potential of mobile phones for educational purposes in a variety of contexts. Recent studies on mobile devices in different learning environments have shown students' ability to improve learning performance [32]-[34]. Although there have been several studies on the factors that influence learners' decision to use M-learning, most of these studies are conducted in developed countries [16], while M-learning is also attracting the attention of educators in developing countries in recent years. This paper is based on the TAM to study the factors affecting students' M-learning adoption in Vietnam - a developing country in the Asian-Pacific region. 


\subsection{Overview of the Technology Acceptance Model (TAM)}

Acceptance of a new system and technology is the first step to the success of any system. Several theories have been presented to explore the factors that determine user acceptance of the Technology and Information System [17] to solve this problem. The technology acceptance model developed by [17] appears to be the most widely used technology acceptance model. TAM (See Fig. 1) includes the core variables of user motivation (i.e., perceived ease of use, perceived usefulness, and attitude toward technology) and outcome variables (i.e., behavioral intentions, technology use). Among these variables, perceived usefulness (PU) and perceived ease of use (PEU) are considered main variables that directly or indirectly explain the results [35].

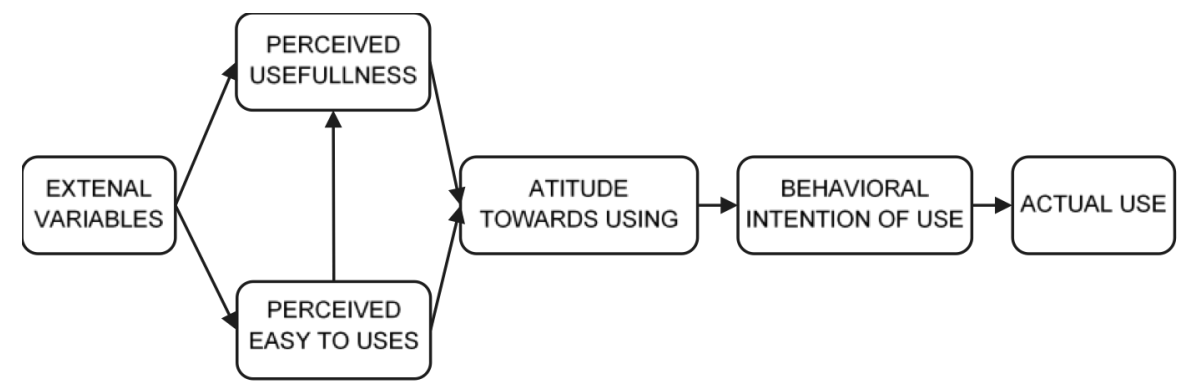

Fig. 1. TAM (Davis, 1989)

After many studies, a series of next-generation TAMs was proposed. There are at least three different versions of the TAM model made between 1986 and 2013 [35], some of which only considered USE as an outcome variable, others considered BI and USE as an ATT outcome. [36] conducted a comprehensive analysis of a TAM version containing external variables (See Fig. 2).

This model has been applied in many studies, including studies on mobile technology acceptance in education. [37] synthesized 124 correlation matrices from 114 empirical TAM studies $(\mathrm{N}=34,357$ teachers $)$ and checked the appropriateness of TAM and its versions. Some studies include [38]: measuring users' behavioral intention who use YouTube as a learning resource and identifying the factors that influence this behavioral intention of applying YouTube as a learning resource. Another study considered the factors that influence the application and use of an instructor's Internet-based course management system. Using data from an online survey of a university lecturer $(\mathrm{N}=191)$, a path analysis shows that easy system usage significantly impacts usefulness, as proposed by TAM [39]. Using the TAM, [40] has confirmed that the educational system with technology users can help them transfer and acquire knowledge.

The application of TAM to m-learning has also been studied by many authors on different subjects of undergraduate and graduate students at two universities in Taiwan [41] and medical students at Coimbra University [42]; Bachelor of Primary Education at the University [43]. These studies all use the extended TAM. One 
common point of these studies is that users maintain a positive attitude towards Mlearning and consider M-learning an effective tool. It can be seen that the studies focused on clarifying factors influencing the decision to use M-learning of undergraduate and graduate students. There is no study for high school students. This article will clarify the factors influencing high school student's decision to use Mlearning in Vietnam and compare these factors with other subjects previously studied.

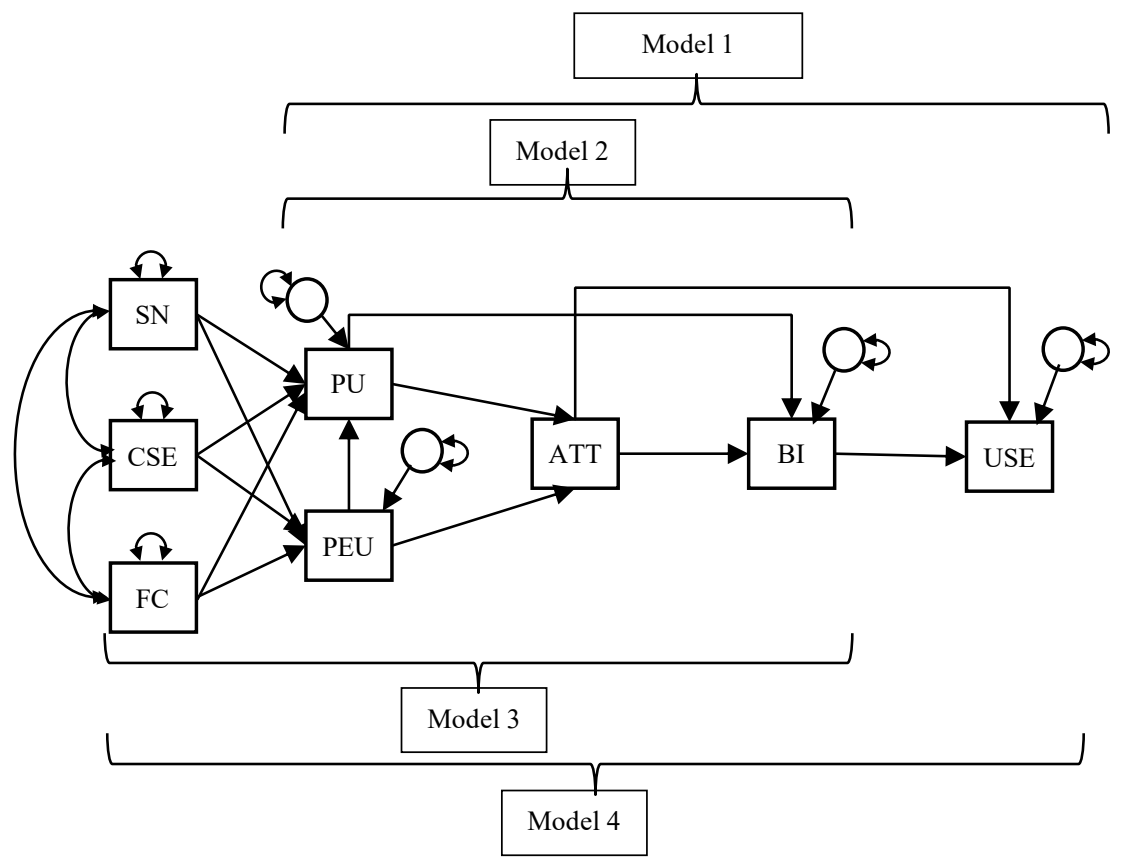

Fig. 2. Models describing teachers' technology acceptance with and without external variables.

\section{$3 \quad$ Methods}

With this exploratory study, we want to determine the factors influencing high school student's decision to use M-learning. It can be seen that a students' attitude towards accepting and using M-learning will improve the effectiveness of participating in activities through mobile technology in learning support. Based on previous studies, the items of each work in the research model have been adapted [17], [36], we select factors from the model, which can influence the choice of using M-learning in Vietnam. Specifically, Davis (1989) measured the Perceived usefulness (PU) (three items) and Perceived ease of use (PE) (three items). The self-efficacy (CSE) consisted of three items, facilitating conditions (FC) consisted of two items adapted from Abdullah \& Ward (2016). Scales were adapted from Abdullah \& Ward (2016) to measure subjective norms (SN)-the influence of others on the user's decision to use or not to use the technology (three items) and Attitude (ATT) (two items). 
Behavioral intention (BI) (four items) was based on Abdullah \& Ward (2016). We build a research model with relationships between factors, as shown in Fig. 3.

With the above model, we have conducted a study to evaluate the following hypotheses:

\subsection{Hypotheses}

H1: Perceived usefulness has a positive effect on attitude.

H2: Perceived ease of use has a positive effect on attitude.

H3: Self-efficacy positively has a positive effect on behavioral intention.

H4: Subjective norms have a positive effect on behavioral intention.

H5. Mobility and convenience have a positive effect on behavioral intention.

H6. Attitude has a positive effect on behavioral intention.

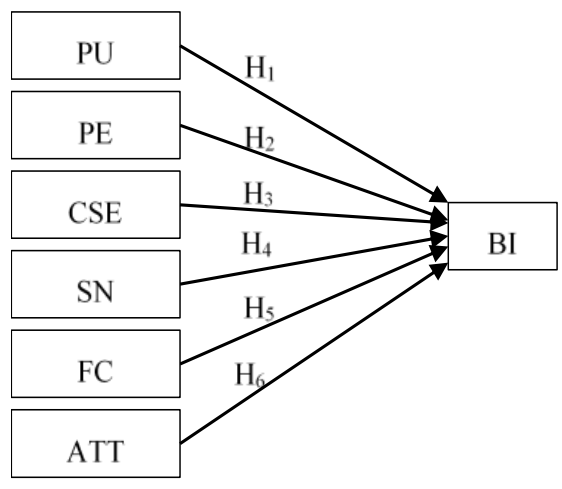

Fig. 3. Proposal for six factors model

Before conducting the official survey, we conducted a pilot survey with 50 students, the number of students of three high schools representing the North, Central, and South of Vietnam, to test the significance and understandability of the questionnaire. After receiving the results from the pilot test, we reviewed and adjusted to achieve a final questionnaire with 19 items (see Table 1. ).

\subsection{Materials}

The questionnaire consists of 19 questions according to a 5-point Likert scale with five levels of strongly disagree, disagree, neither agree nor disagree, agree, and strongly agree for each opinion.

In the official survey, we use the online survey choice to collect data. The time for conducting the survey and data collection is half a month (from April 12th, 2019 to May 30th, 2019). 


\subsection{Participants}

Experimental data used in this study was collected through a survey of high school students on their participation in M-learning. The survey was sent to 10 high schools in Vietnam $(\mathrm{N}=400)$ : 02 specialized high schools and eight other public high schools. The survey of all schools was not feasible at that time due to time and resource constraints, so high schools were selected based on their representation in education (Specialized and public high schools); number of years of establishment (newly opened and long-standing school); scale (large and small schools); geographical location (north, central and south of Vietnam);

\subsection{Procedure}

The experiment took place with high school students in Thai Nguyen, Hanoi, Dong Thap, and An Giang provinces. When the questionnaire link was sent, the participants completed the questionnaire with written instructions sent to the educational institutions. On average, each student takes about 15-20 minutes to complete the questionnaire given by the study.

Table 1. Coding factors of the study model

\begin{tabular}{|c|c|c|c|c|}
\hline Variable & Description & Type & Items & Questionnaires \\
\hline $\mathrm{PU}$ & $\begin{array}{l}\text { Perceived } \\
\text { usefulness }\end{array}$ & Independent & 3 & $\begin{array}{l}\text { (PU1) The use of M-learning will save me much time } \\
\text { (PU2) M-learning will improve my learning } \\
\text { efficiency } \\
\text { (PU3) Overall, I find M-learning useful }\end{array}$ \\
\hline $\mathrm{PE}$ & $\begin{array}{l}\text { Perceived } \\
\text { ease of use }\end{array}$ & Independent & 3 & $\begin{array}{l}\text { (PE1) The use of M-learning will not require much of } \\
\text { my effort } \\
\text { (PE2) Interaction with M-learning is easy for me to } \\
\text { understand } \\
\text { (PE3) I think M-learning is easy to use }\end{array}$ \\
\hline CSE & Self-efficacy & Independent & 3 & $\begin{array}{l}\text { (CSE1) I know I can use mobile technologies even if } \\
\text { I have not used them in an educational environment } \\
\text { yet. } \\
\text { (CSE2) I can design educational activities using } \\
\text { mobile devices } \\
\text { (CSE3) I can use a mobile device in class even if no } \\
\text { one is helping me }\end{array}$ \\
\hline $\mathrm{FC}$ & $\begin{array}{l}\text { Facilitating } \\
\text { conditions }\end{array}$ & Independent & 2 & $\begin{array}{l}\text { (FC1) It is convenient to access M-learning anytime } \\
\text { and anywhere } \\
\text { (FC2) Mobility is an outstanding advantage of M- } \\
\text { learning }\end{array}$ \\
\hline ATT & $\begin{array}{l}\text { Subjective } \\
\text { norms } \\
\text { Attitude }\end{array}$ & $\begin{array}{l}\text { Independent } \\
\text { Independent }\end{array}$ & 3 & $\begin{array}{l}\text { (SN1) I use M-learning because my friends also use } \\
\text { this type of learning } \\
\text { (SN2) Teachers introduced us to use M-learning } \\
\text { (SN3) I use M-learning because I find that celebrities } \\
\text { also participate in this type of learning } \\
\text { (ATT1) I want to use M-learning } \\
\text { (ATT2) I have a positive opinion of M-learning } \\
\end{array}$ \\
\hline BI & $\begin{array}{l}\text { Behavioral } \\
\text { intention }\end{array}$ & Dependent & 3 & $\begin{array}{l}\text { (BI1) I plan to use M-learning when available } \\
\text { (BI2) If I were asked to express my opinion on M- } \\
\text { learning, I intended to say something favorable } \\
\text { (BI3) In the future, I plan to use M-learning regularly }\end{array}$ \\
\hline
\end{tabular}




\subsection{Design and analyses}

We use multivariate regression analysis to analyze and evaluate the proposed hypotheses. The collected questionnaire was into SPSS software to conduct the data analysis. The missing data values were checked and processed by using the frequency command in SPSS version 20 to filter invalid input values in addition to conventional values and checking the original questionnaire to adjust the data correctly. After the data set was cleaned, data analysis was conducted to verify the scale. We used Cronbach's Alpha composite reliability coefficients to evaluate the reliability of each scale. If these are greater than 0.6 , the constructs are reliable. In this study, we used exploratory factor analysis (EFA) to evaluate the value of the scale of elements in the model. The convergent value and the discriminant value of the scale create more significant factors from the assessment of the convergent value. If the factor loadings on items in the constructs are larger than 0.5 , the constructs in the model achieve convergence validity. We used the $95 \%$ confidence intervals of the correlation coefficients between constructs in the model regarding discriminant validity. If the $95 \%$ confidence intervals of the correlation coefficients do not contain one value, the constructs in the model reach discriminant validity. After analyzing the exploratory factor, we put the new factor table into a multivariate regression analysis to consider the impact of the factors in the model, thereby testing the proposed hypothesis with statistical significance at level 5\%.

\section{$4 \quad$ Results}

\subsection{Descriptive statistic}

After the process of missing (responses were rejected because they did not answer all the items in the survey, their data was not included in the analysis), the study collected responses from 238 high school students, including 150 male and 88 female students (completion rate of valid questionnaires was $59.5 \%$ of participants). The age of surveyed students is from 16 to 18 years (equivalent to grade 10 to 12), of which the number of 10th graders responding to the questionnaire accounts for $153 / 238$ (64.3\%) (see Table 2.) .

Especially with the question "The mobile devices you are using," $94.1 \%$ of the students answered that they use a mobile phone, and the time spent more than three years accounts for 132/238 (55.5\%). However, when asked "Your experience with Mlearning," the number of students who answered "I know what M-learning is and have used it before" only accounts for 21/238 (8.8\%) (Table 2. ). 
Table 2. Personal Information Description of the surveyed samples

\begin{tabular}{|c|c|c|c|}
\hline & & Count & Column N \% \\
\hline \multirow{3}{*}{ Sex } & Male & 150 & $63.0 \%$ \\
\hline & Female & 88 & $37.0 \%$ \\
\hline & Total & 238 & $100.0 \%$ \\
\hline \multirow{3}{*}{ Class } & Grade 10 & 153 & \\
\hline & Grade 11 & 32 & \\
\hline & Grade 12 & 53 & \\
\hline \multirow{2}{*}{ TB1_MTCT } & No & 0 & $0.0 \%$ \\
\hline & Yes & 238 & $100.0 \%$ \\
\hline \multirow{2}{*}{ TB2_TBCT } & No & 98 & $41.2 \%$ \\
\hline & Yes & 140 & $58.8 \%$ \\
\hline \multirow{2}{*}{ TB3_MTB } & No & 163 & $68.5 \%$ \\
\hline & Yes & 75 & $31.5 \%$ \\
\hline \multirow{3}{*}{ TB4_DTDD } & No & 14 & $5.9 \%$ \\
\hline & Yes & 224 & $94.1 \%$ \\
\hline & Total & 238 & $100.0 \%$ \\
\hline \multirow{3}{*}{ Used time } & Less than one year & 37 & \\
\hline & From 1 to 3 years & 69 & \\
\hline & More than three years & 132 & \\
\hline \multirow{3}{*}{ Frequency of use } & Less than 1 hour & 10 & \\
\hline & From 1 to 3 hours & 107 & \\
\hline & Over 3 hours & 121 & \\
\hline \multirow{4}{*}{ Experience } & No answer & 69 & \\
\hline & Unknown and unused & 73 & \\
\hline & Know but have not used & 75 & \\
\hline & Already known and used & 21 & \\
\hline
\end{tabular}

\subsection{Testing factors and measuring scales}

Evaluating the reliability of Cronbach's Alpha scale with the data set collected, we have Table 3.

Table 3. Reliability estimates

\begin{tabular}{|l|l|c|c|}
\hline \multicolumn{1}{|c|}{ Factors } & \multicolumn{1}{c|}{ Observed variables } & Cronbach's $\boldsymbol{\alpha}$ & Corrected item-total correlation \\
\hline PU & PU1, PU2, PU3 & 0.773 & $>0.3$ \\
\hline PE & PE1, PE2, PE3 & 0.866 & $>0.3$ \\
\hline CES & CES1, CES2, CES3 & 0.644 & $>0.3$ \\
\hline FC & FC1, FC2 & 0.602 & $>0.3$ \\
\hline SN & SN1, SN2, SN3 & 0.801 & $>0.3$ \\
\hline ATT & ATT1, ATT2 & 0.775 & $>0.3$ \\
\hline
\end{tabular}

According to Table 3, the Cronbach's alpha reliability coefficient of factors is from 0.602 to 0.866 , which satisfies the reliability requirements $(\geq 0.6)$, and the corrected item-total correlation is greater than 0.3 . This proves that the observed variables in the factors are highly consistent, and the measuring scale of factors is sufficiently reliable. 


\subsection{Testing the factors affecting the decision to use $M$ - learning}

The exploratory factor analysis - EFA is used to test the factors that affect students' decision to use $\mathrm{M}$ - learning. According to the initial hypothesis, there are six factors (16 observed variables). The results of factor analysis in Tables 2 and 3 indicate that:

- The KMO coefficient is used to evaluate the conformity of the exploratory factor analysis, reaching a value of 0.778 , which satisfies the condition of $0.5 \leq \mathrm{KMO} \leq$ 1. This indicates that the exploratory factor analysis is accepted with the studied data set.

- Sig Barlett's Test is used to evaluate whether observed variables in a factor are correlated and whether the exploratory factor analysis is significant or not. According to Table 3 , sig $=0.000<0.05$ shows that the exploratory factor analysis is suitable for the variables under consideration.

- Through the rotated component matrix table, 16 observed variables will be converted to 5 factors, and the position of 16 variables has been revised, specifically as in 0

Table 4. KMO and Bartlett's Test

\begin{tabular}{|l|l|c|}
\hline \multicolumn{2}{|c|}{ Kaiser-Meyer-Olkin Measure of Sampling Adequacy. } & $\mathbf{. 7 7 8}$ \\
\hline \multirow{3}{*}{ Bartlett's Test of Sphericity } & Approx. Chi-Square & 1499.844 \\
\cline { 2 - 3 } & df & 120 \\
\cline { 2 - 3 } & Sig. & .000 \\
\hline
\end{tabular}

Table 5. Rotated Component Matrix

\begin{tabular}{|c|c|c|c|c|c|}
\hline & \multicolumn{5}{|c|}{ Component } \\
\hline & 1 & 2 & 3 & 4 & 5 \\
\hline ATT1 & .835 & & & & \\
\hline SN3 & .823 & & & & \\
\hline SN2 & .822 & & & & \\
\hline ATT2 & .821 & & & & \\
\hline SN1 & .733 & & & & \\
\hline PE1 & & .873 & & & \\
\hline PE3 & & .866 & & & \\
\hline PE2 & & .865 & & & \\
\hline PU1 & & & .829 & & \\
\hline PU3 & & & .819 & & \\
\hline PU2 & & & .793 & & \\
\hline CES1 & & & & .861 & \\
\hline CES3 & & & & .824 & \\
\hline CES2 & & & & .526 & \\
\hline FC1 & & & & & .826 \\
\hline $\mathrm{FC} 2$ & & & & & .762 \\
\hline
\end{tabular}


Table 6. Revised factors and variables

\begin{tabular}{|l|l|l|}
\hline \multicolumn{1}{|c|}{ Factors } & \multicolumn{1}{|c|}{ Observed variables } & \multicolumn{1}{c|}{ Variable types } \\
\hline $\mathrm{X} 1$ (PU) & PU1, PU2, PU3 & Independent \\
\hline $\mathrm{X} 2$ (pe) & PE1, PE2, PE3 & Independent \\
\hline $\mathrm{X} 3$ (ces) & CES1, CES2, CES3 & Independent \\
\hline $\mathrm{X} 4$ (FC) & FC1, FC2 & Independent \\
\hline $\mathrm{X} 5$ (new) & SN1, SN2, SN3, ATT1, ATT2 & Independent \\
\hline $\mathrm{Y}(\mathrm{BI})$ & $\mathrm{BI}$ ) BI2, BI3 & Dependent \\
\hline
\end{tabular}

\subsection{Multiple regression analysis}

The metric to assess the conformity of a standard linear model is the adjusted coefficient R2 (Adjusted R Square), which reflects the explanatory degree for dependent variables of independent variables in the regression model. Table 5 shows that $\mathrm{R} 2 \mathrm{a}=0.516$, indicating that the independent variables $\mathrm{X} 1, \mathrm{X} 2, \mathrm{X} 3, \mathrm{X} 4, \mathrm{X} 5$ explain $51.6 \%$ of the change in the dependent variable $Y$, the remaining $48.4 \%$ of the change in $\mathrm{Y}$ will be due to variables other than the studied model.

0 shows that the sig value of the $\mathrm{F}$ test is used to test the conformity of the regression model. The statistic $\mathrm{F}=51.614$ with the probability of rejection has a sig value $=0.000$, sufficient to conclude that the value of R2a is accepted. The model uses multiple linear regression, consistent with the collected data set.

Table 7. Model Summary

\begin{tabular}{|c|c|c|c|c|c|}
\hline Model & $\mathbf{R}$ & R Square & Adjusted R Square & $\begin{array}{c}\text { Std. Error of the } \\
\text { Estimate }\end{array}$ & Durbin-Watson \\
\hline 1 & $.726^{\mathrm{a}}$ & .527 & .516 & .539 & 2.178 \\
\hline
\end{tabular}

Table 8. ANOVA $^{\mathrm{a}}$

\begin{tabular}{|c|l|c|c|c|c|c|}
\hline \multicolumn{2}{|c|}{ Model } & Sum of Squares & df & Mean Square & F & Sig. \\
\hline \multirow{3}{*}{1} & Regression & 75.097 & 5 & 15.019 & 51.614 & $.000 \mathrm{~b}$ \\
\cline { 2 - 7 } & Residual & 67.510 & 232 & .291 & & \\
\cline { 2 - 7 } & Total & 142.607 & 237 & & & \\
\hline
\end{tabular}

Multicollinearity is the phenomenon of independent variables with close correlation to each other (linear relationship), and it is invalid to explain the change of dependent variables in the regression model. This means that the occurrence of multicollinearity will cause difficulties in analyzing the effects of each independent variable on dependent variables.

According to the reference materials, if the variance inflation factor -VIF is less than 10 (actually less than 2), there will be no collinearity. With the results obtained in Table 7. , the independent variables have VIF $<2$, indicating that variables in the model are independent of each other, there is no multicollinearity.

According to Table 4., we have a new analytical model as follows:

$$
\mathrm{Y}=\mathrm{f}(\mathrm{X} 1, \mathrm{X} 2, \mathrm{X} 3, \mathrm{X} 4, \mathrm{X} 5) \text {. }
$$


These new factors are quantified by the average of observed variables in that factor. Using SPSS, we have regression results as shown in Table 9.

Table 9. Coefficients ${ }^{\mathrm{a}}$

\begin{tabular}{|c|c|c|c|c|c|c|c|}
\hline \multirow{2}{*}{ Model } & \multicolumn{2}{|c|}{$\begin{array}{c}\text { Unstandardized } \\
\text { Coefficients }\end{array}$} & \multirow{2}{*}{$\begin{array}{c}\begin{array}{c}\text { Standardized } \\
\text { Coefficients }\end{array} \\
\text { Beta } \\
\end{array}$} & \multirow[t]{2}{*}{$\mathbf{t}$} & \multirow{2}{*}{ Sig. } & \multicolumn{2}{|c|}{ Collinearity Statistics } \\
\hline & $B$ & Std. Error & & & & Tolerance & VIF \\
\hline Constant & -1.574 & .328 & & -4.797 & .000 & & \\
\hline $\mathrm{pu}$ & .510 & .066 & .369 & 7.766 & .000 & .904 & 1.106 \\
\hline pe & .154 & .044 & .173 & 3.526 & .001 & .848 & 1.179 \\
\hline ces & .168 & .055 & .150 & 3.042 & .003 & .838 & 1.193 \\
\hline $\mathrm{fc}$ & .232 & .042 & .274 & 5.468 & .000 & .813 & 1.230 \\
\hline new & .296 & .045 & .323 & 6.625 & .000 & .859 & 1.165 \\
\hline
\end{tabular}

Sig value. of the t-test (testing the significance of Beta regression coefficient) in Fig. 4 of factors X1 (PU), X2 (pe), X3 (ces), X4 (fc), X5 (new) are all less than 0.05. Therefore, we conclude that these independent variables impact the dependent variable $\mathrm{Y}(\mathrm{BI})$. The impact level of variables depends on the standard regression coefficient.

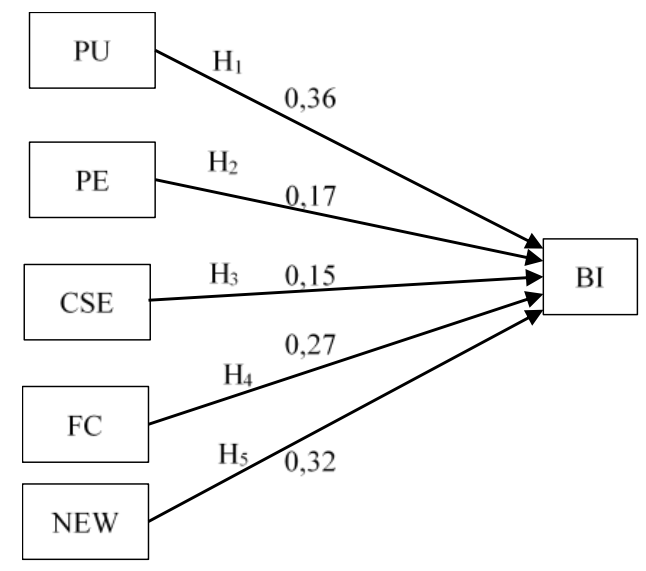

Fig. 4. Model of performance levels of the independent variables to the dependent variables

Standardized regression equation:

$$
\mathrm{Y}=0.369 * \mathrm{X} 1+0.173 * \mathrm{X} 2+0.150 * \mathrm{X} 3+0.274 * \mathrm{X} 4+0.323 * \mathrm{X} 5
$$

Thus, the independent variables X1 (PU), X5 (new) have the most influence on the dependent variable $\mathrm{Y}$, the variable $\mathrm{X} 3$ (ces) has the least influence. 


\section{Discussion and Conclusion}

According to the initial theoretical model with six hypotheses, the six factors affecting the decision to use M-learning by high school students: Perceived usefulness, Perceived ease of use, Self-efficacy, Subjective norms, mobility, convenience, attitude. However, through SPSS for analyzing and processing actual survey data, there are only five basic factors X1 (PU), X2 (pe), X3 (ces), X4 (fc), X5 (new), affecting the decision to use M-learning by high school students.

Factor X1 presents three basic issues: saving much time, improving learning efficiency, and bringing usefulness. In the standardized regression equation, the factor $\mathrm{X} 1$ has the highest Beta coefficient (Beta $=0.369)$, showing that X1 influences students' decision to use M-learning. This result is consistent with previous studies [41]. The results indicate that users know that users' usefulness is the most important in expressing their attitudes when using M-learning.

The factor X5 (new) presents two main issues: the attitude of learners and the impact of the objects that affect M-learning. In the standardized regression equation, the factor X5 has the second-highest Beta coefficient (Beta $=0.323$ ), which shows that the influence of X2 on learning outcomes is only behind the influence of usefulness. These findings were aligned with previous studies where students' selflearning ability were found to challenging for using M-learning [19].

The factor X4 (fc) presents mobility and convenience when using M-learning. In the standardized regression equation, the factor $\mathrm{X} 4$ also has a relatively high Beta coefficient (Beta $=0.274$ ), which shows that $\mathrm{X} 4$ is also a factor that significantly influences the decision to use M-learning by high school students.

The two factors X2 (ces) and X3 (pe) are self-efficacy factors for mobile technology and ease of use. In the standardized regression equation, the factors $\mathrm{X} 2$, $\mathrm{X} 3$ have a Beta coefficient of 0.173 and 0.150 , respectively, which shows that the two factors' influence on learning outcomes is nearly equal. At the same time, we can see that these two factors have the most minor influence on using M-learning among the factors measured. The mobile phone skills of students can explain it; students seemed to adopt the ability to use mobile phones quickly [44].

This study aims to determine the factors that influence the decision to use Mlearning by high school students in Vietnam. The conclusions of this study have some implications for suppliers and researchers interested in M-learning. Firstly, this study shows that perceived usefulness (PU), attitudes of learners, and the impact of different objects (SN, ATT) are the main factors that determine the user's perception of Mlearning. However, PU has more influence than SN and ATT.

The above study results show that the most important thing to encourage students to choose M-learning in their studying is that the educators should pay attention to the design of appropriate courses to save time, improve learning outcomes for students, and increase the mobility of learners. Besides, it is also necessary to introduce the convenience of courses to learners through many different channels. 


\section{Recommendations}

Based on the research on the application of M-learning and the factors affecting the decisions to use M-learning in students' learning, further research is needed to implement M-learning as effective [45-47].

Firstly, it is necessary to research, design, and edit m-learning materials to support students in learning to exploit the advantages of M-learning and prove the connection with the curriculum, content, and teaching purposes.

Secondly, it is necessary to identify the appropriate forms to exploit several mobile phone applications in learning activities under experimental conditions.

\section{$7 \quad$ References}

[1] J. A. Hyman, M. T. Moser, and L. N. Segala, "Electronic reading and digital library technologies: understanding learner expectation and usage intent for mobile learning," Educ. Technol. Res. Dev., vol. 62, no. 1, pp. 35-52, 2014. https://doi.org/10.1007/s11423$\underline{013-9330-5}$

[2] J. Keengwe and M. Bhargava, "Mobile learning and integration of mobile technologies in education," Educ. Inf. Technol., vol. 19, no. 4, pp. 737-746, 2014. https://doi.org/10.1007 $\underline{\text { s10639-013-9250-3 }}$

[3] P. Lavín-Mera, P. Moreno-Ger, and B. Fernández-Manjón, "Development of educational videogames in m-learning contexts," in 2008 Second IEEE International Conference on Digital Game and Intelligent Toy Enhanced Learning, 2008, pp. 44-51. https://doi.org/10. $\underline{1109 / \text { digitel.2008.21 }}$

[4] D. Stevens and A. Kitchenham, "An analysis of mobile learning in education, business, and medicine," in Models for interdisciplinary mobile learning: Delivering information to students, IGI Global, 2011, pp. 1-25. https://doi.org/10.4018/978-1-60960-511-7.ch001

[5] J. G. Caudill, "Mobile Computing: Parallel developments," Int. Rev. Res. Open Distance Learn., vol. 8, no. 2, p. 13, 2007.

[6] S. Hussin, M. Radzi Manap, Z. Amir, and P. Krish, "Mobile Learning Readiness among Malaysian Students at Higher Learning Institutes," Asian Soc. Sci., vol. 8, no. 12, 2012. https://doi.org/10.5539/ass.v8n12p276

[7] D. Keegan, "The future of learning: From eLearning to mLearning.," 2002.

[8] J.-C. Hong, M.-Y. Hwang, W.-T. Wong, H.-C. Lin, and C.-M. Yau, "Gender differences in social cognitive learning at a technological project design," Int. J. Technol. Des. Educ., vol. 22, no. 4, pp. 451-472, 2012. https://doi.org/10.1007/s10798-011-9152-x

[9] S. Ahmed and D. Parsons, "Abductive science inquiry using mobile devices in the classroom," Comput. Educ., vol. 63, pp. 62-72, 2013. https://doi.org/10.1016/j.compedu. $\underline{2012.11 .017}$

[10] H.-W. Huang, C.-W. Wu, and N.-S. Chen, "The effectiveness of using procedural scaffoldings in a paper-plus-smartphone collaborative learning context," Comput. Educ., vol. 59, no. 2, pp. 250-259, 2012. https://doi.org/10.1016/j.compedu.2012.01.015

[11] S. Mahamad, M. N. Ibrahim, and S. Mohd Taib, "M-learning: A New Paradigm of Learning Mathematics in Malaysia," Int. J. Comput. Sci. Inf. Technol., vol. 2, no. 4, pp. 76-86, 2010. https://doi.org/10.5121/ijcsit.2010.2407

[12] Z. Yan, Q. Chen, and C. Yu, "The Science of Cell Phone Use," Int. J. Cyber Behav. Psychol. Learn., vol. 3, no. 1, pp. 7-18, 2013. 
[13] F. Martin and J. Ertzberger, "Here and now mobile learning: An experimental study on the use of mobile technology," Comput. Educ., vol. 68, pp. 76-85, 2013. https://doi.org/10. 1016/j.compedu.2013.04.021

[14] J.-L. Shih, C.-W. Chuang, and G.-J. Hwang, "An inquiry-based mobile learning approach to enhancing social science learning effectiveness," J. Educ. Technol. Soc., vol. 13, no. 4, pp. 50-62, 2010.

[15] C.-C. Yang, G.-J. Hwang, C.-M. Hung, and S.-S. Tseng, “An evaluation of the learning effectiveness of concept map-based science book reading via mobile devices," J. Educ. Technol. Soc., vol. 16, no. 3, pp. 167-178, 2013.

[16] M. Bano, D. Zowghi, M. Kearney, S. Schuck, and P. Aubusson, "Mobile learning for science and mathematics school education: A systematic review of empirical evidence," Comput. Educ., vol. 121, no. February, pp. 30-58, 2018. https://doi.org/10.1016/j.compe du. 2018.02 .006

[17] F. D. Davis, "Perceived usefulness, perceived ease of use, and user acceptance of information technology," MIS Q. Manag. Inf. Syst., vol. 13, no. 3, pp. 319-339, 1989. https://doi.org/10.2307/249008

[18] H. der Heijden, "User acceptance of hedonic information systems," MIS Q., pp. 695-704, 2004. https://doi.org/10.2307/25148660

[19] T. T. Phuong Thao, L. D. Thai, H. T. Thanh, T. Tran, L. T. Tuyet Trinh, and Q. H. Vuong, "Mobile learning for high-school mathematics as a path to better sustainability in a fastchanging society: An exploratory study from Vietnam," Probl. Perspect. Manag., vol. 17, no. 2, 2019. https://doi.org/10.21511/ppm.17(2).2019.30

[20] A. Murphy, W. Midgley, and H. Farley, "Mobile learning trends among students in Vietnam," Commun. Comput. Inf. Sci., vol. 479, pp. 197-204, 2014. https://doi.org/10. 1007/978-3-319-13416-1 18

[21] M. Al-Emran, H. M. Elsherif, and K. Shaalan, "Investigating attitudes towards the use of mobile learning in higher education," Comput. Human Behav., vol. 56, pp. 93-102, 2016. https://doi.org/10.1016/j.chb.2015.11.033

[22] N. S. Alzaza and A. R. Yaakub, "Students ' Awareness and Requirements of Mobile Learning Services in the Higher Education Environment," vol. 3, no. 1, pp. 95-100, 2011. https://doi.org/10.3844/ajebasp.2011.95.100

[23] A. Matias and D. F. Wolf, "Engaging students in online courses through the use of mobile technology," Cutting-edge Technol. High. Educ., vol. 6, no. D, pp. 115-142, 2013.

[24] T. Kristiansen, "M-learning: Experiences from the use of WAP as a supplement in learning," Unpubl. Rep. a Pilot Proj. Co-operation between Insite, Ericsson, Telenor Mob. It Fornebu Knowation, 2001.

[25] P. Losch, "The digital campus primer [EB]," Sun Microsystems Inc, 2003.

[26] P. Dorouka, S. Papadakis, and M. Kalogiannakis, "Tablets and apps for promoting robotics, mathematics, STEM education and literacy in early childhood education," Int. J. Mob. Learn. Organ., vol. 14, no. 2, pp. 255-274, 2020. https://doi.org/10.1504/ijmlo.2020. 10026334

[27] S. Papadakis, M. Kalogiannakis, and N. Zaranis, "Designing and creating an educational app rubric for preschool teachers," Educ. Inf. Technol., vol. 22, no. 6, pp. 3147-3165, 2017. https://doi.org/10.1007/s10639-017-9579-0

[28] S. Papadakis. Apps to Promote Computational Thinking Concepts and Coding Skills in Children of Preschool and Pre-Primary School Age. In Mobile Learning Applications in Early Childhood Education (pp. 101-121). IGI Global, 2020. https://doi.org/10.4018/978$\underline{1-7998-1486-3 . \operatorname{ch} 006}$ 
[29] S. Papadakis, M. Kalogiannakis, and N. Zaranis, "Educational apps from the Android Google Play for Greek preschoolers: A systematic review," Comput. Educ., vol. 116, pp. 139-160, 2018. https://doi.org/10.1016/j.compedu.2017.09.007

[30] S. Papadakis and M. Kalogiannakis, "Mobile educational applications for children: What educators and parents need to know," Int. J. Mob. Learn. Organ., vol. 11, no. 3, pp. 256277, 2017. https://doi.org/10.1504/ijmlo.2017.085338

[31] K. E. K. Lim, K. K. J. Lim, and others, "Engaging students with m-learning," in Proceedings of ITE Teachers' Conference, 2006.

[32] K. N. Chee, N. Yahaya, N. H. Ibrahim, and M. N. Hasan, "Review of mobile learning trends 2010-2015: A meta-analysis," Educ. Technol. Soc., vol. 20, no. 2, pp. 113-126, 2017.

[33] M. Kearney, K. Burden, and T. Rai, "Investigating teachers ' adoption of signature mobile pedagogies," Comput. Educ., vol. 80, pp. 48-57, 2015. https://doi.org/10.1016/j.compedu. $\underline{2014.08 .009}$

[34] M. Drolia, E. Sifaki, S. Papadakis, and M. Kalogiannakis, "An Overview of Mobile Learning for Refugee Students: Juxtaposing Refugee Needs with Mobile Applications' Characteristics," mdpi.com, 2020. https://doi.org/10.3390/challe11020031

[35] N. Marangunić and A. Granić, "Technology acceptance model: a literature review from 1986 to 2013," Univers. Access Inf. Soc., vol. 14, no. 1, pp. 81-95, 2015. https://doi.org/10.1007/s10209-014-0348-1

[36] F. Abdullah and R. Ward, "Developing a General Extended Technology Acceptance Model for E-Learning (GETAMEL) by analyzing commonly used external factors," Comput. Human Behav., vol. 56, pp. 238-256, 2016. https://doi.org/10.1016/ j.chb.2015.11.036

[37] R. Scherer, F. Siddiq, and J. Tondeur, "Computers \& Education The technology acceptance model ( TAM ): A meta-analytic structural equation modeling approach to explaining teachers' adoption of digital technology in education," Comput. Educ., vol. 128, no. 0317, pp. 13-35, 2019. https://doi.org/10.1016/j.compedu.2018.09.009

[38] N. Chintalapati, V. Srinivas, and K. Daruri, "Examining the Use of YouTube as a Learning resource in higher education: Scale development and Validation of TAM model," Telemat. Informatics, 2016. https://doi.org/10.1016/j.tele.2016.08.008

[39] S. Y. Park, "An Analysis of the Technology Acceptance Model in Understanding University Students' Behavioral Intention to Use e-Learning," Educ. Technol. Soc., vol. 12, no. 3, pp. 150-162, 2009.

[40] N. S. Alzaza, A. R. Yaakub, and T. Farahat, "Applying the Technology Acceptance Model to Online Learning in the Egyptian Universities," Procedia - Soc. Behav. Sci., vol. 64, no. 1, pp. 95-104, 2012. https://doi.org/10.1016/j.sbspro.2012.11.012

[41] J. H. Huang, Y. R. Lin, and S. T. Chuang, "Elucidating user behavior of mobile learning: A perspective of the extended technology acceptance model," Electron. Libr., vol. 25, no. 5, pp. 585-598, 2007. https://doi.org/10.1108/02640470710829569

[42] L. Briz-Ponce, A. Pereira, L. Carvalho, J. A. Juanes-Méndez, and F. J. Garcl'lia-Peñalvo, "Learning with mobile technologies--Students' behavior," Comput. Human Behav., vol. 72, pp. 612-620, 2017. https://doi.org/10.1016/j.chb.2016.05.027

[43] J. C. Sánchez-Prieto, S. Olmos-Migueláñez, and F. J. Garcia-Peñalvo, "MLearning and pre-service teachers: An assessment of the behavioral intention using an expanded TAM model," Comput. Human Behav., vol. 72, pp. 644-654, 2017. https://doi.org/10.1016/ j.chb.2016.09.061 
[44] A. Althunibat, "Determining the factors influencing students' intention to use m-learning in Jordan higher education," Comput. Human Behav., vol. 52, pp. 65-71, Jun. 2015. https://doi.org/10.1016/j.chb.2015.05.046

[45] S. Papadakis, and M. Kalogiannakis, "A research synthesis of the real value of selfproclaimed mobile educational applications for young children." Mobile learning applications in early childhood education, 1-19, 2020. https://doi.org/10.4018/978-1-79981486-3.ch001

[46] S. Papadakis, "Tools for evaluating educational apps for young children: a systematic review of the literature." Interactive Technology and Smart Education, Vol. ahead-of-print No. ahead-of-print., 2020. https://doi.org/10.1108/itse-08-2020-0127

[47] S.Papadakis, M., Kalogiannakis, M., and N. Zaranis, "Teaching mathematics with mobile devices and the Realistic Mathematical Education (RME) approach in kindergarten." Advances in Mobile Learning Educational Research, 1(1), 5-18, 2021.

\section{Authors}

Trinh Le Thi Tuyet is a Ph.D. in Mathematics Education and works as a Lecturer at Dong Thap University, Vietnam. Her main research interests include mathematics education, evaluation, and assessment in education and innovation of teaching and learning methods in high school. Email: letrinh1282@gmail.com; ORCID: https://or cid.org/0000-0003-3970-9773

Thao Phuong Thi Trinh is an Associate Professor, Doctor of Education, and a senior lecturer at the Thai Nguyen University of Education, Vietnam. Associate Professor Trinh Thi Phuong Thao has published many articles in prestigious scientific journals in ISI, Scopus. The main research interests of Associate Professor Trinh Thi Phuong Thao include mathematics education, information, and communication technology application in education, teacher training, and fostering and ethnic education. email: trinhphuongthao@dhsptn.edu.vn; ORCID: https://orcid.org/00000001-6277-4907

Hang Thu Thi Nguyen is working at the Faculty of Basic Sciences at Thai Nguyen University of Agriculture and Forestry. She is a Ph.D. student at the Thai Nguyen University of Education. Her main research direction is to innovate teaching and assessment methods towards developing learners' capacity. Besides, she has a scientific research orientation in the context of industrial revolution 4.0. email: nguyenhang@tuaf.edu.vn; ORCID: https://orcid.org/0000-0003-2737-833X

Thanh Chi Nguyen is an Associate Professor of Education Studies, graduated with a Ph.D. in Didactic Mathematics at Grenoble I University (French Republic), currently a lecturer at the University of Education, Hanoi National University. The main research areas are Didactic Math; Application of Information Technology in teaching and learning Maths; Professional development of math teachers; Developing school curriculum in Maths; STEM education; Mathematical and Computer Thinking in general teaching. Email: thanhnc@vnu.edu.vn; ORCID: https://orcid.org/0000-00 01-8533-2925

Trung Tran is Professor of Mathematics Education, Director of the Vietnam Academy for Ethnic Minorities, Hanoi, Vietnam, a lecturer at the University of 
Education, Hanoi National University. Professor Tran Trung has published many articles in prestigious international journals in ISI, Scopus, and monograph editors of international publishers (SpringerNature, Taylor \& Francis, DeGruyter). At the same time, Professor Tran Trung is also a Guest Editor for some special subjects of the Sustainability Magazine (SSCI, IF2018 = 2,592). The main research areas of Professor Tran Trung are ethnic education, educational management, public policy, and teaching methods. Besides, Professor Tran Trung also participates in interdisciplinary research between education and mathematics, computer science, economics and technology, and the development of scientific research skills. email: trungt1978@gmail.com; ORCID: https://orcid.org/0000-0002-0459-7284

Article submitted 2021-02-18. Resubmitted 2021-04-20. Final acceptance 2021-04-20. Final version published as submitted by the authors. 